\title{
Rain Rate and Rain Attenuation Geographical Map for Satellite System Planning in Ghana
}

\author{
Stephen Akobre \\ Dept. of Computer Science \\ University for Development Studies \\ Navrongo, Ghana
}

\author{
Mohammed Ibrahim Daabo \\ Dept. of Computer Science \\ University for Development Studies \\ Navrongo, Ghana
}

\author{
Abdul-Mumin Salifu \\ Dept. of Computer Science \\ University for Development Studies \\ Navrongo, Ghana
}

\begin{abstract}
Good signal reception depends on a reliable communication link. However, as the signal travels through the communication medium, several factors affect the quality of the signal at the receiver. In $\mathrm{Ku}$ band digital satellite transmission, rain is the major cause of link impairment. Global rain rate and rain attenuation prediction models have been developed to predict rain rate and rain attenuation at various locations. These models have not been applied and tested with measured data to determine their prediction accuracy in the Ghanaian tropical region. In this paper, the Moupfouma and International Telecommunication Union Recommendation (ITU-R) rain rate models were applied and compared with measured local 1-minute data for Kumasi. The result was used to select an appropriate prediction model to be applied to all 22 synoptic stations across Ghana. The ITU-R rain attenuation model was then used to predict the rain attenuation for Ghana. The values obtained were used to develop a rain rate and rain attenuation geographical map for Ghana using the inverse-distance weighting method and Arc GIS software. As Ghana migrates from analogue to digital satellite television broadcasting, it is imperative to investigate the effect of rain on the signal. This will serve as a tool for system designers to determine the appropriate effective isotropic radiated power (EIRP) and receiver characteristics for Ghana.
\end{abstract}

\section{Keywords}

Rain rate, rain attenuation, Ku band.

\section{INTRODUCTION}

The International Telecommunication Union (ITU) at its Geneva 2006 convention advocated for all countries to migrate from analogue to digital television broadcasting. This is because of the enormous advantage in satellite services provided by higher frequency bands. Also, consumers demand high speed broadband services which cannot be satisfied by existing lower frequency bands due to congestion and bandwidth limitations. Most countries have completed the migration process but Ghana is yet to accomplish this after missing the deadline on a number of occasions. Signals propagated through higher frequencies (above $10 \mathrm{GHz}$ ) are adversely affected by rain leading to low quality and less availability of the signal at the receiver. Rain drops absorb and scatter radio waves resulting in insufficient power at the receiver to allow for proper decoding of data at an acceptable bit error rate. This affects the signal availability and dependability objectives. The severity of rain impairments increases with frequency and varies with regional locations (Ajayi, 1996). Since rain was established to be the major cause of signal attenuation at $\mathrm{Ku}$ band and due to the varying nature of rainfall across locations, many researchers have conducted experiments in their climatic regions to measure the rain rate and attenuation. These studies have been carried out mostly in the temperate regions. But the severity of rain effect on the signal, are more pronounce at the tropics and equatorial regions where intense rainfall events are common as compared to the temperate regions. This is reported in the work of Ajayi (1996), Moupfouma (1985) and Ojo and Omotosho (2013).

Satellite system design requires as input 1-minute rain rate data with various exceedance probabilities. Based on this many researchers have conducted experiments on their local climatological regions to measure 1-minute rain rate and attenuation. In regions where there are enough data coverage, prediction models have been proposed. But there is a lack of 1-minute integration time rain rate data across the world, especially in developing countries like Ghana. The International Telecommunication Union Recommendation (ITU-R P. 837-6, 2012) has provided global maps, where data can be extrapolated based on some data from regions where they are available, mostly the temperate regions. However recent research suggest that these extrapolated data when used for tropical and equatorial regions will either underestimate or overestimate rain attenuation values ( Emiliani et al,2004; Ojo and Omotosho, 2013). This situation is caused by the limited availability of 1-minute integration time rain rate data from tropical and equatorial countries for modeling and testing of prediction models (Ojo et al, 2009). In the absence of 1minute rain rate data however, study shows that daily and hourly rainfall accumulations are readily available by meteorological agencies to satisfy traditional requirements such as agriculture, hydrology, weather forecasting and forest management ( Fashuyi et.al,2006; Owolawi and Affullo, 2007). Knowledge of 1-minute rain rate is essential in radio communication system design. A method for converting the available rain rate cumulative distribution $(\mathrm{CD})$ is useful for system designers.

In this paper as Ghana is migrating from analogue to digital television broadcasting and rain will be the major cause of signal impairment, it will be prudent to determine the rain rate values for Ghana. The applicability of the global models in the Ghanaian tropical environment is also unknown. Since there is lack of 1-minute rain rate data for Ghana but available longer integration time data, there is the need to use rain rate conversion models to convert the available hourly data into 1minute rain rate statistics for the 22 selected locations in Ghana. These locations are synoptic stations. Two global models, the ITU-R and Moupfouma are applied in the Ghanaian tropical climate for the first time. This resulted in two divergent values and an experiment was conducted in one of the 22 synoptic stations (Kumasi) in Ghana to measure 1minute rain rate locally to compare with prediction values of the global models. This is necessary in order to make an unbiased choice of which model is suitable to be applied 
throughout the Ghanaian tropical climate for the determination 1-minute rain rate values. This will lead to the development of rain rate and rain attenuation geographical map for Ghana. The overall result from these maps will be a useful tool for preliminary study on the effects of rain on the $\mathrm{Ku}$ band signal propagated in the Ghanaian tropical climate.

\section{THE GHANAIAN TROPICAL CLIMATE}

Ghana is located on latitude $7.9465 \mathrm{~N}$ and longitude 1.0232 oW in Sub-Saharan Africa. The climate of Ghana has two main seasons; the wet and dry seasons. Northern Ghana experiences its rainy seasons from May to mid-October while Southern Ghana experiences its rainy season from March to mid-November. In the Southern part of Ghana, there is a bimodal rainy season: April through June and September through November. As stated earlier, most developing countries like Ghana have daily rainfall accumulations data to satisfy traditional requirements such as agriculture. The agroecological zones in Ghana is divided into four main zones by the Ghana Meteorological Agency (Owusu and Waylen, 2009). These zones are the Forest Zone (Abetifi, Akim Oda, Axim, Ho, Koforidua, Kumasi, Akatsi and Takoradi), the Coastal Zone (Accra, Ada, Akatsi, Saltpond and Tema), the Transition Zone ( Kete-Krachie, Sunyani , Kintampo and Wenchi) and Northern Zone (Bole, Navrongo, Tamale, Wa and Yendi). The forest zone covers the tropical forest and the south western coast of the country. The Coastal zone covers the dry coastal strip of South western Ghana. The transition zone also covers the middle part of Ghana whiles the Northern zone covers the northern part of the Country, which experiences similar rainfall totals as that of the other zones, but has a single wet season. Figure 1 shows a map of the 22 synoptic stations and the agro-ecological zones in Ghana.

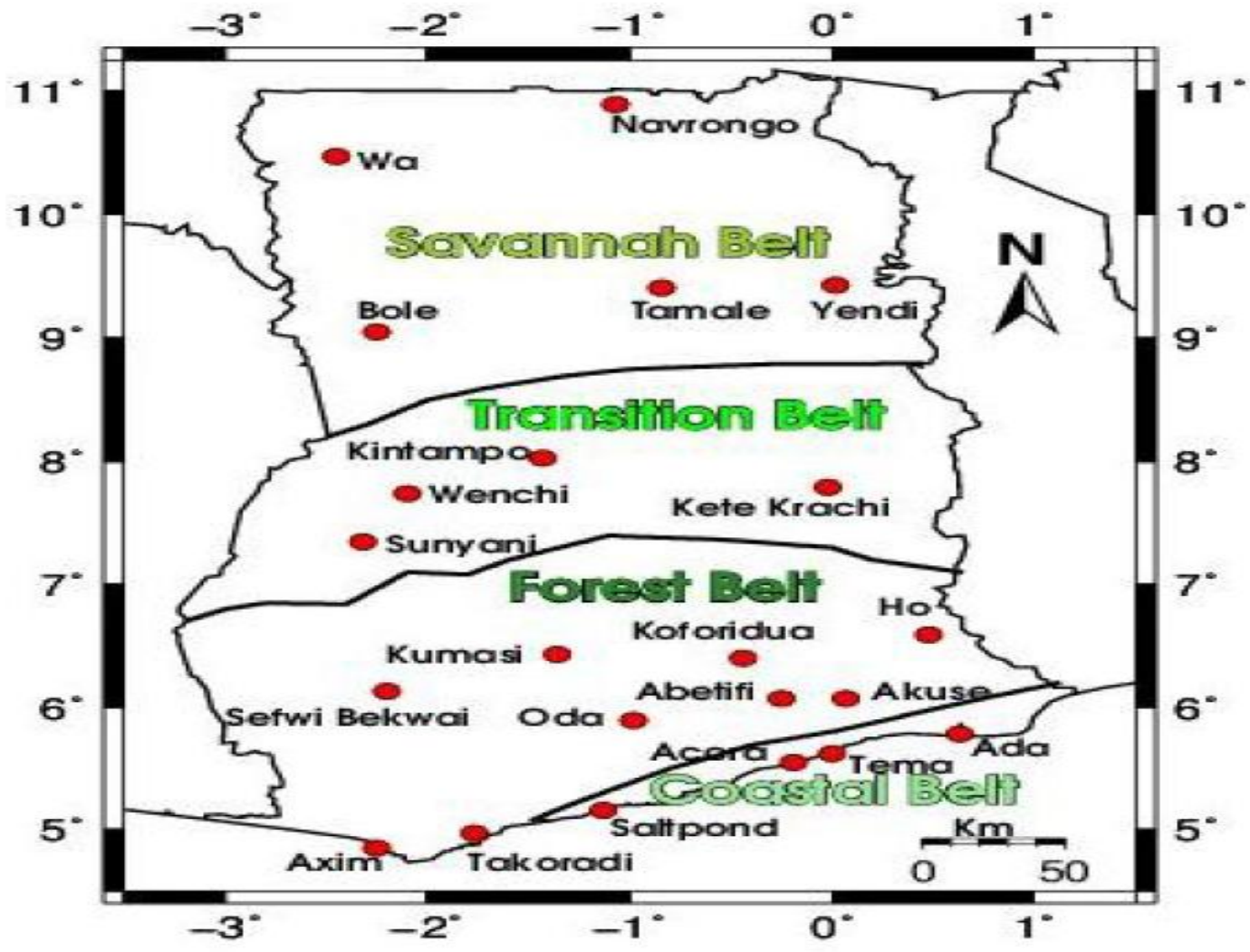

Fig 1. Synoptic stations of Ghana: Source (Manzanas et al.2014)

The average annual rainfall in Ghana is about $5829.76 \mathrm{~mm}$ compared to a global average of $860 \mathrm{~mm}$ and in South Africa of about $500 \mathrm{~mm}$ (Ojo and Owolawi, 2014).

In order to develop maps with spatial distribution over Ghana it is important to consider the fact that Ghana like most developing countries lack 1-minute integration time data but has available daily rainfall accumulations. Data for longer integration time therefore had to be used to determine the rain rate for Ghana using the Moupfouma model. The Ghana meteorological Agency (GMA) provided daily rainfall data for over 30 years for all 22 synoptic stations in Ghana. However a five year dataset from 2013 to 2018 was used for this study. In order to develop a climatic map of rain rate and rain attenuation for Ghana, it will be necessary that stations be well distributed over the entire country. The 22 synoptic stations will therefore be classified into four climatic zones for the purpose of this study. Northen Zone (Navrongo, Wa, Tamale, Bole, Yendi), Middle zone (Kumasi, Sunyani, SefwiBekwai, Wenchi, Kete-Krachi, Abetifi), Southern zone (Akuse, Ho, Koforidua, Akim-Oda, Akatsi), Coastal zone ( Accra, Tema, Axim, Saltpond, Ada-Foah , Takoradi). Each climatic Zone consist of at least five stations. The 22 stations are well distributed across the country. The rain gauge used by the GMA is the standard $127 \mathrm{~mm}$ in accordance with the World Meteorological Organization (WMO) standard. Table 1 gives the various climatic zones and data summary for each station. 
Table 1. Synoptic stations used and summary of each station.

\begin{tabular}{|c|c|c|c|c|c|c|}
\hline $\begin{array}{l}\text { CLIMATIC } \\
\text { ZONE }\end{array}$ & STATION & $\begin{array}{l}\text { LATITUDE } \\
\left({ }^{\circ} \mathrm{N}\right)\end{array}$ & $\begin{array}{l}\text { LONGITUDE } \\
(\text { E OR } \text { 'W })\end{array}$ & $\begin{array}{l}\text { ALTITUDE } \\
\text { (M) }\end{array}$ & $\begin{array}{l}\text { ANNUAL } \\
\text { RAINFALL } \\
(\mathrm{MM})\end{array}$ & $\begin{array}{c}\text { DURATION } \\
\text { (YEARS) }\end{array}$ \\
\hline \multirow[t]{5}{*}{ NORTHERN } & NAVRONGO & $10.54 \mathrm{~N}$ & 01.06W & 213.4 & 5087.3 & 5 \\
\hline & WA & $10.03 \mathrm{~N}$ & 02.30W & 322.7 & 5243.3 & 5 \\
\hline & TAMALE & $09.33 \mathrm{~N}$ & $00.51 \mathrm{~W}$ & 168.8 & 5405.1 & 5 \\
\hline & BOLE & $09.02 \mathrm{~N}$ & 02.29W & 299.5 & 5843.4 & 5 \\
\hline & YENDI & $09.27 \mathrm{~N}$ & $00.01 \mathrm{~W}$ & 195.2 & 6585.6 & 5 \\
\hline \multirow[t]{6}{*}{ MIDDLE } & KUMASI & $06.43 \mathrm{~N}$ & $01.36 \mathrm{~W}$ & 286.3 & 7120.1 & 5 \\
\hline & SUNYANI & $07.20 \mathrm{~N}$ & $02.20 \mathrm{~W}$ & 308.8 & 6518.6 & 5 \\
\hline & $\begin{array}{l}\text { SEFWI- } \\
\text { BEKWAI }\end{array}$ & $06.12 \mathrm{~N}$ & $02.20 \mathrm{~W}$ & 170.8 & 7163.1 & 5 \\
\hline & WENCHI & $07.45 \mathrm{~N}$ & $02.06 \mathrm{~W}$ & 338.9 & 6285.5 & 5 \\
\hline & $\begin{array}{l}\text { KETE- } \\
\text { KRACHI }\end{array}$ & $07.49 \mathrm{~N}$ & $00.02 \mathrm{~W}$ & 122.0 & 6668.3 & 5 \\
\hline & ABETIFI & $06.40 \mathrm{~N}$ & $00.45 \mathrm{~W}$ & 594.7 & 6636.4 & 5 \\
\hline \multirow[t]{5}{*}{ SOUTHERN } & AKUSE & $6.06 \mathrm{~N}$ & $00.07 \mathrm{E}$ & 17.4 & 4993.3 & 5 \\
\hline & $\mathrm{HO}$ & $6.36 \mathrm{~N}$ & $00.28 \mathrm{E}$ & 157.6 & 6137.5 & 5 \\
\hline & KOFORIDUA & $6.06 \mathrm{~N}$ & $00.15 \mathrm{~W}$ & 166.5 & 6061.8 & 5 \\
\hline & AKIM-ODA & $5.56 \mathrm{~N}$ & $00.59 \mathrm{~W}$ & 139.4 & 7270.6 & 5 \\
\hline & AKATSI & $6.07 \mathrm{~N}$ & $00.48 \mathrm{E}$ & 53.6 & 4388.4 & 5 \\
\hline \multirow[t]{6}{*}{ COASTAL } & ACCRA & $05.36 \mathrm{~N}$ & $00.10 \mathrm{~W}$ & 67.7 & 3723.5 & 5 \\
\hline & TEMA & $05.37 \mathrm{~N}$ & $00.00 \mathrm{E}$ & 14.0 & 3630.4 & 5 \\
\hline & SALTPOND & $05.12 \mathrm{~N}$ & $01.04 \mathrm{~W}$ & 43.9 & 4541 & 5 \\
\hline & AXIM & $4.52 \mathrm{~N}$ & $02.14 \mathrm{~W}$ & 37.8 & 9251.2 & 5 \\
\hline & ADA-FOAH & $05.47 \mathrm{~N}$ & $00.38 \mathrm{E}$ & 5.2 & 4226.1 & 5 \\
\hline & TAKORADI & $04.53 \mathrm{~N}$ & $01.46 \mathrm{~W}$ & 4.6 & 5474.2 & 5 \\
\hline
\end{tabular}

\section{RAIN RATE MODELS AND RECENT TREND IN AFRICA}

There are a number of methodologies formulated with the aim of determining best performing models for a particular geographical area. Some of these models include Moupfouma and Martin (1995), Rice and Holmberg (1973), ITU P. 837-6 (2012) which is now in its sixth revision, Karasawa and Matsudo (1991) among others. Detailed descriptions of these models can be found in refereed journals and are not discussed here. Rain rate and attenuation studies have been carried out quite extensively in the temperate regions. However the focus has drifted to tropical and equatorial regions. But there is still more to be done in Africa and subsaharan Africa to contribute to propagation research in this region. In Africa, some studies have been done by Owolawi and Afullo (2007), Fashuyi et al.(1988), Owolawi et al.(2008) in South Africa. As well as Ajayi et al.(1988), Ojo et al.(2008), Omotosho et al.(2013) and Ajayi and Ofoche (1984) in Nigeria. However, the situation is different for Ghana. There has been little or no research on rain rate and attenuation studies in Ghana.

In this paper, the Moupfouma and Martin model (1995) was used to convert the available data into 1-minute rain rate statistics and the ITU rain rate model to determine the rain rate for 22 synoptic stations in Ghana for the first time. An experiment was also conducted to measure 1-minute rain rate locally in one of the synoptic stations (Kumasi) for the first time. The result was be compared to the values obtained by applying Moupfouma and Martin and ITU values for Kumasi. 
This is necessary in order to make an unbiased choice of which of the two models is suitable to be applied in the Ghanaian tropical climate. One minute rain rate and attenuation maps were then developed for Ghana using the inverse distance method and Arc GIS software. This will serve as a preliminary tool for satellite system planning.

\section{SELECTION OF A SUITABLE RAIN RATE AND RAIN ATTENUATION PREDICTION MODEL}

During the selection of a model for a particular site, care must be taken because most of the models are developed based on parameters available to the developer. According to studies by Emiliani et al.(2009), Mandeep(2009), COST-255 (2002), models are best fit when local parameters are used. Among the most widely available models mentioned above, results have shown that the Moupfouma model can best describe 1minute rain rate distribution in both tropical and sub-tropical regions. Additionally, the model has been known to approximate a log-normal distribution of the low rain rates and a gamma distribution of high rain rate. Based on this the Moupfouma model was selected for this study. Moupfouma found that the 1-minute rain rate $\mathrm{CD}$ could be expressed as follows:

$P(R \geq r)=10^{-4}\left(\frac{R_{0.01}}{r+1}\right)^{b} e^{\left(u\left[R_{0.01}-r\right]\right)}$

Where $r(\mathrm{~mm} / \mathrm{h})$ represents the rain rate exceeded for a fraction of the time, $R_{0.01}(\mathrm{~mm} / \mathrm{h})$ is the rain rate exceeded at 0.01 percent of time in an average year, and $b$ is approximated by the expression in Equation (2):

$b=\left(\frac{r-R_{0.01}}{R_{0.01}}\right) \ln \left(1+\frac{r}{R_{0.01}}\right)$

The parameter $u$ in Equation (1) governs the slope of the rain rate cumulative distribution and depends on the local climatic conditions and geographical features. For tropical and subtropical localities, $u$ is given in Equation (3) as

$u=\frac{4 \ln 10}{R_{0.01}} e^{\left(-\lambda\left[\frac{r}{R_{0.01}}\right]^{\gamma}\right)}$

Where $\lambda=1.066 \gamma=0.214$

Thus, the Moupfouma model requires three parameters: $\lambda, \gamma$ and $R_{0.01}$. Whereas the first two parameters $\lambda$ and $\gamma$, have been provided. $R_{0.01}$, is estimated using Chebil and Rahman's model. This allows for the usage of long-time mean annual rainfall accumulation, $\mathrm{M}$, at the location of interest.

The power law relationship of the model is given by Equation (4):
$R_{0.01}=\propto M^{\beta}$

Where $\alpha$ and $\beta$ are regression coefficients defined as $\alpha=$ 12.2903 and $\beta=0.2973$

Therefore, using the Moupfouma and Chebil model, the 1minute rain rate cumulative distribution can be fully determined from the long term mean annual rainfall data. The $\mathrm{CD}$ of rainfall rate for 1-minute integration time was obtained using methodologies described in Equation (1) to (4) on daily rainfall data recorded in synoptic hours from the GMA.

Again, the most internationally accepted and widely used model for the prediction of rain rate is the ITU-R rain rate model. It is based on this reason we decided to apply it to the Ghanaian tropical climate. ITU-R recommendation P.837-6 (2012) contains annexes and maps of meteorological parameters that have been obtained using the European Centre for Medium-Range Weather Forecast (ECMWF) ERA-40 reanalysis database, which are recommended for the prediction of rainfall rate statistics with 1-minute integration time, when local measurements are not available. The model uses a database of parameters $\left(P_{r} 6, M t\right.$ and $\left.\beta\right)$, available from the ITU's 3M Group (2008), each of which is matched to a pair of longitude and latitude. This model was also used to determine 1-munite rain rate for 22 synoptic stations in Ghana for comparison with Moupfouma prediction.

For the prediction of rain attenuation, the ITU-R rain attenuation model (ITU-R P.618-11, 2013) was selected. This is because the ITU-R model is widely accepted and recommended as the standard model for predicting rain attenuation globally. It has been reported that the ITU rain attenuation prediction model results were close to the average prediction of a set of results obtained from the application of eight different methodologies (Emiliani et al.,2009; Ojo et al.,2008,2009).

The following are the input parameters needed for the model: point rainfall rate for the location for $0.01 \%$ of an average year $(\mathrm{mm} / \mathrm{h})$, height above sea level of the earth station $(\mathrm{km})$, elevation angle, latitude of the earth station (deg), frequency $(\mathrm{GHz})$ and effective radius of earth $(8500 \mathrm{~km})$.

The detailed step-by-step procedures can be found in the Appendix A of this study. The equations are captured in A1 to A12. The geostationary satellite chosen for this study is Intelsat 17 (IS-17) located $066.04 \mathrm{E}$ with its service footprint at different angles to each station. $\mathrm{A} \mathrm{Ku}$ band downlink frequency of $11.812 \mathrm{GHZ}$ was measured by a spectrum analyzer and used for this study. Table 2 presents some local geometry parameters used for the study.

Table 2. Local geometry parameters used for the study based on Intelsat 17 (IS-17) Geostationary Satellite

\begin{tabular}{|c|c|c|c|c|c|c|}
\hline ZONE & STATION & LATITUDE & $\begin{array}{c}\text { DISH } \\
\text { ELEVATION } \\
\text { ANGLE ( })\end{array}$ & $\begin{array}{c}\text { STATION } \\
\text { HEIGHT (m) }\end{array}$ & $\boldsymbol{\gamma}_{\boldsymbol{R}}(\mathbf{d B} / \mathbf{k m})$ & $\boldsymbol{L}_{\boldsymbol{E}}(\mathbf{k m})$ \\
\hline NORTHERN & NAVRONGO & $10.54 \mathrm{~N}$ & 14.305 & 213.4 & 1.9977 & 9.5513 \\
\hline & WA & $10.03 \mathrm{~N}$ & 14.211 & 322.7 & 2.3402 & 9.3539 \\
\hline & TAMALE & $09.33 \mathrm{~N}$ & 14.462 & 168.8 & 1.9998 & 9.9026 \\
\hline & BOLE & $09.02 \mathrm{~N}$ & 14.262 & 299.5 & 2.3584 & 9.5183 \\
\hline & YENDI & $09.27 \mathrm{~N}$ & 14.319 & 195.2 & 2.0821 & 9.8151 \\
\hline MIDDLE & KUMASI & $06.43 \mathrm{~N}$ & 13.843 & 286.3 & 2.6595 & 9.0462 \\
\hline
\end{tabular}




\begin{tabular}{|c|c|c|c|c|c|c|}
\hline & SUNYANI & $07.20 \mathrm{~N}$ & 13.064 & 308.8 & 2.5803 & 10.1722 \\
\hline & $\begin{array}{c}\text { SEFWI- } \\
\text { BEKWAI }\end{array}$ & $06.12 \mathrm{~N}$ & 13.911 & 170.8 & 3.0028 & 9.1996 \\
\hline & WENCHI & $07.45 \mathrm{~N}$ & 13.45 & 338.9 & 2.4551 & 10.0015 \\
\hline & KETE- & $07.49 \mathrm{~N}$ & 14.812 & 122 & 2.4366 & 8.8085 \\
& KRACHI & & & & & \\
\hline & ABETIFI & $06.40 \mathrm{~N}$ & 13.542 & 594.7 & 2.8049 & 9.0129 \\
\hline & AKUSE & $6.06 \mathrm{~N}$ & 15.345 & 17.4 & 3.1365 & 7.9985 \\
\hline & HOUTHERN & $6.36 \mathrm{~N}$ & 15.99 & 157.6 & 2.7193 & 8.0106 \\
\hline & KOFORIDUA & $6.06 \mathrm{~N}$ & 15.217 & 166.5 & 3.1468 & 8.0341 \\
\hline & AKIM-ODA & $5.56 \mathrm{~N}$ & 15.819 & 139.4 & 2.8941 & 7.4674 \\
\hline & AKATSI & $6.07 \mathrm{~N}$ & 15.612 & 53.6 & 3.1437 & 7.8947 \\
\hline & ACCRA & $05.36 \mathrm{~N}$ & 15.265 & 67.7 & 3.3803 & 7.7382 \\
\hline & TEMA & $05.37 \mathrm{~N}$ & 15.515 & 14 & 3.3773 & 8.5205 \\
\hline & AXIM & $4.52 \mathrm{~N}$ & 13.451 & 37.8 & 3.5919 & 8.3047 \\
\hline & SALTPOND & $05.12 \mathrm{~N}$ & 13.233 & 43.9 & 3.2453 & 8.7653 \\
\hline & ADA-FOAH & $05.47 \mathrm{~N}$ & 15.931 & 5.2 & 3.3799 & 7.5535 \\
\hline & TAKORADI & $04.53 \mathrm{~N}$ & 13.814 & 4.6 & 3.5123 & 8.2345 \\
\hline
\end{tabular}

\section{EXPERIMENTAL SETUP TO MEASURE 1-MINUTE RAIN RATE IN KUMASI}

The experimental setup was located in Kumasi, one of the 22 synoptic stations in Ghana. This station is in the middle zone of Ghana on latitude $06.43 \mathrm{~N}$ and longitude $01.36^{\circ} \mathrm{W}$ at an altitude of 286.3 meters above sea level. An optical rain gauge was mounted at $70 \mathrm{~cm}$ above ground level. The orifice of the rain gauge was $0.01 \mathrm{~mm}$. Inside the rain gauge is a sponge that collects dust particles around the orifice to prevent clogging which can lead to rainfall underestimation. The orifice takes count of the number of drops that passes through collector per minute for any rainfall event. At the end of each day, a file is created in Comma Separated Values (CSV) by the arduino software. Data is retrieved and continuous updated by wifi connection using a shortcut through Windows Secure Copy Protocol software. The data period was from January 2016 to December 2018. Figure 2 shows the experimental setup used for the study.

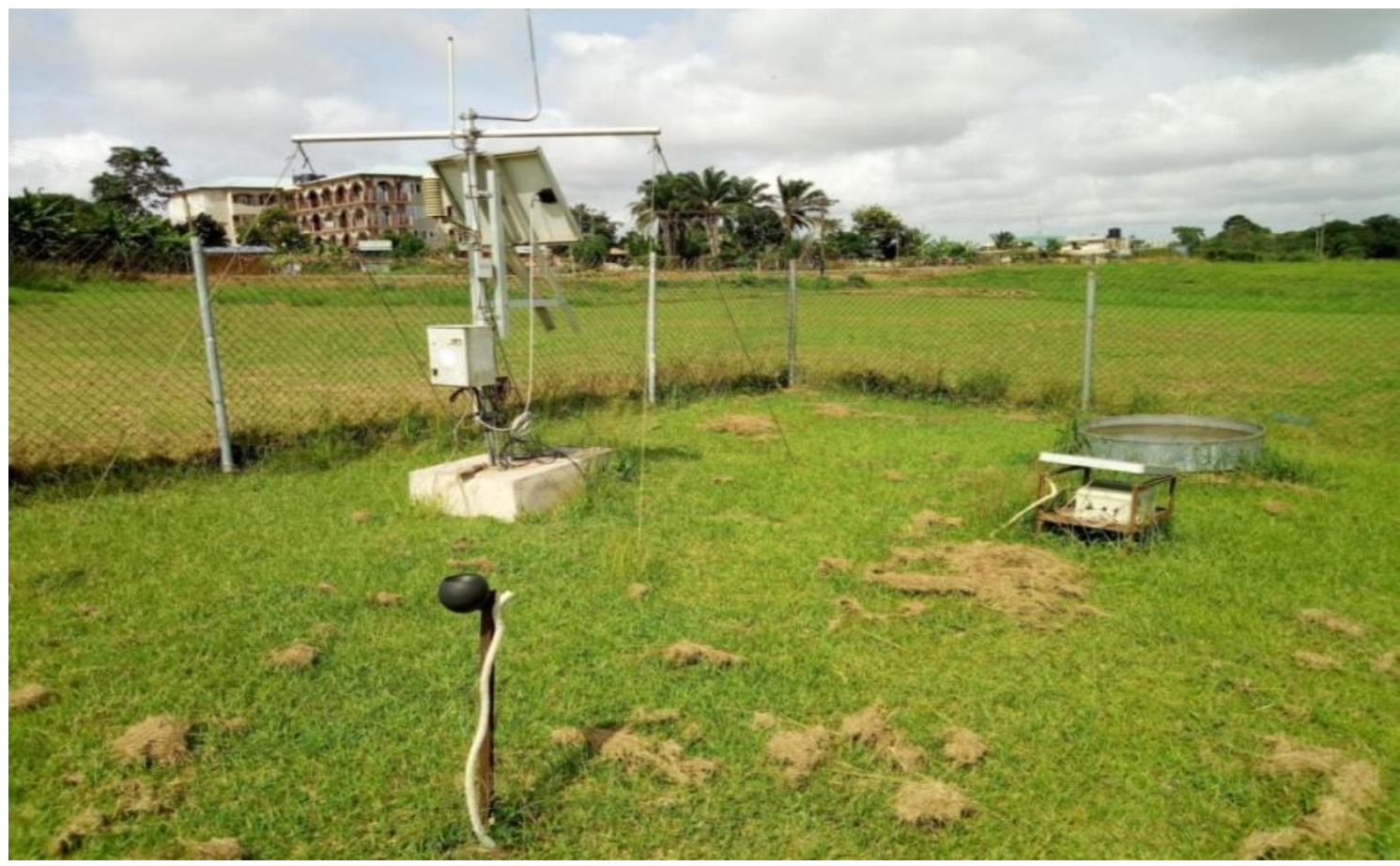

Fig 2: Experimental setup for measuring 1-minute rain rate for Kumasi. 


\section{COMPARISM OF PREDICTION MODELS WITH MEASURED 1- MINUTE DATA FOR KUMASI}

Before presenting the rain rate and rain attenuation maps for Ghana, it is necessary to make an unbiased choice of which rain rate model to apply to all 22 synoptic stations for Ghana since the two global models applied gave divergent values. Measuring minutely data is a very difficult task to undertake. The experiment could not be conducted on all sites. Nevertheless, measured data for 1-minute rain rate was available for one of the sites, Kumasi can allow for a point-

Table 3. Rain rate Cumulative Distribution probabilities for Kumasi with prediction models

\begin{tabular}{|c|c|c|c|c|c|}
\hline \multicolumn{1}{|c|}{ Table 3. Rain rate Cumulative Distribution probabilities for Kumasi with prediction models } \\
\hline $\begin{array}{c}\text { Percentage of } \\
\text { time (\%) }\end{array}$ & $\begin{array}{c}\text { Moupfouma } \\
(\mathrm{mm} / \mathrm{h})\end{array}$ & ITU-R (mm/h) & Measured (mm/h) & $\begin{array}{c}\text { Percentage Error } \\
\text { Moupfouma }(\%)\end{array}$ & $\begin{array}{c}\text { Percentage Error } \\
\text { ITU-R (\%) }\end{array}$ \\
\hline 1 & 6.8 & 2.8398 & 4.0 & 70 & 29.00 \\
\hline 0.3 & 18.8 & 8.0505 & 12.1 & 55.4 & 33.47 \\
\hline 0.1 & 38.3 & 19.58 & 25.31 & 21.5 & 22.64 \\
\hline 0.03 & 70.6 & 41.11 & 58.1 & 42.4 & 13.473 \\
\hline 0.01 & 106.4 & 64.636 & 74.7 & 41.9 & 12.11 \\
\hline 0.005 & 129.6 & 80.23 & 91.3 & 35.6 & 14.81 \\
\hline 0.003 & 146.3 & 91.92 & 107.9 & 27.9 & 18.656 \\
\hline 0.002 & 159.2 & 101.272 & 124.5 & 27.9 & 16.814 \\
\hline 0.001 & 180.4 & 117.375 & 141.1 & & \\
\hline
\end{tabular}

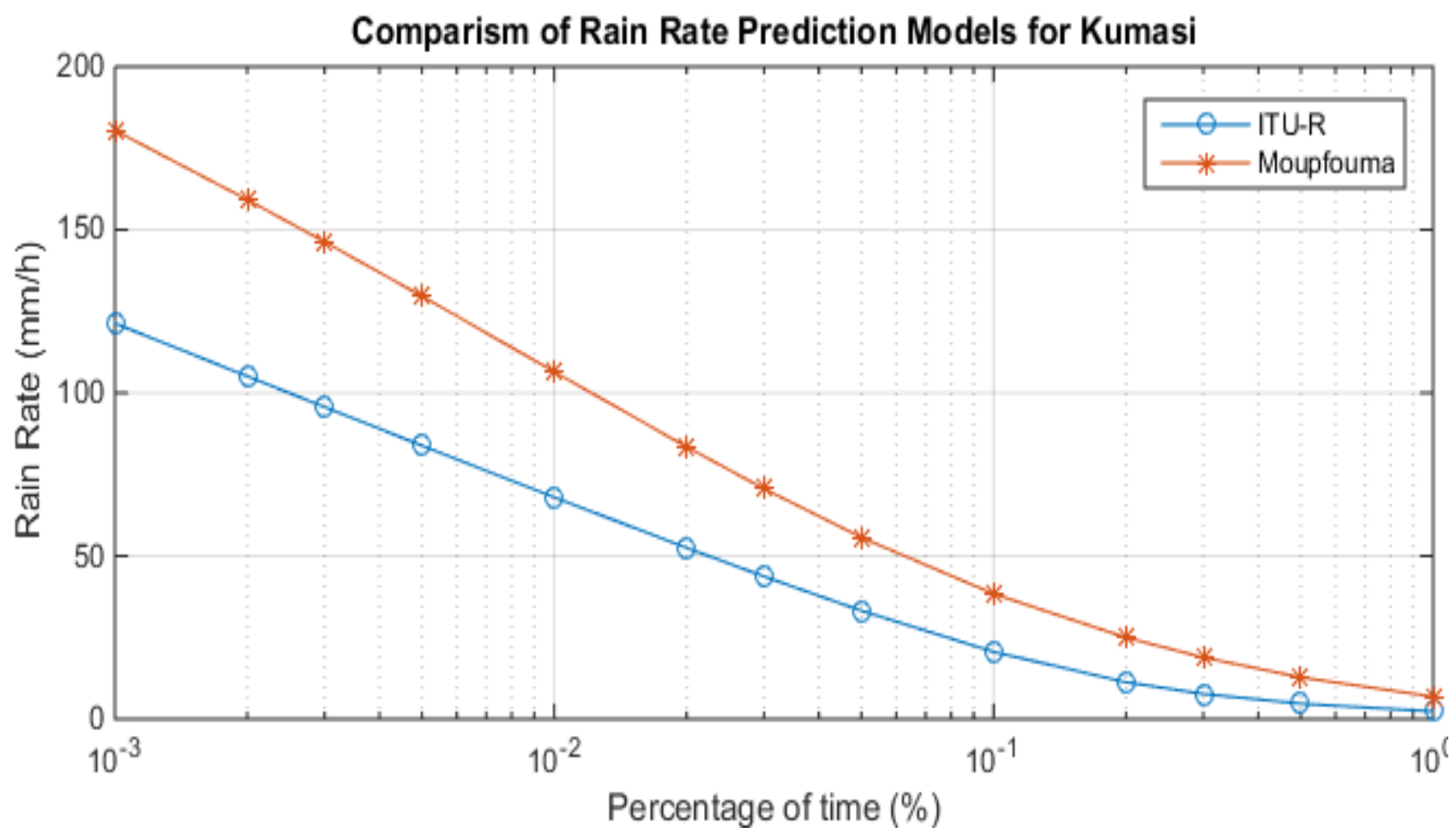

Fig 3: Rain rate prediction values for Kumasi using Moupfouma and ITU-R models. wise comparison. With this empirical approach, a scientific choice can be made between the two global models to determine their suitability for predicting rain rate in the Ghanaian tropical region. MATLAB software was used to determine the Cummulative Distribution (CD) of the 1-minute data. This was compared to the $\mathrm{CD}$ values for Moupfouma and ITU-R. The results are shown in Table 3. Figure 3 shows the graph of the $\mathrm{CD}$ using rain rate prediction models of Moupfouma and ITU-R values for Kumasi. Figure 4 shows the graph of the $\mathrm{CD}$ of the prediction models with measured data for Kumasi. 


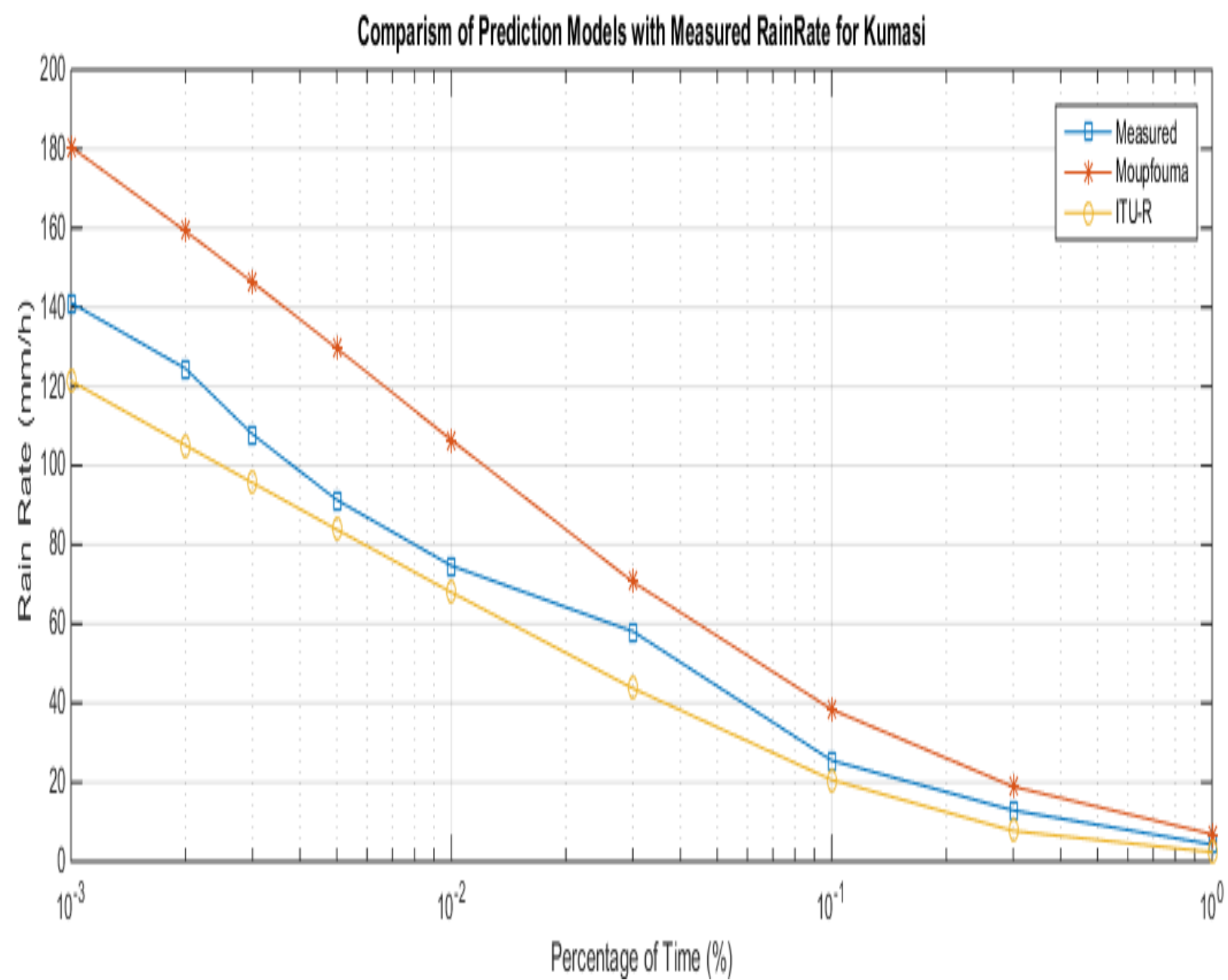

Fig 4: Comparism of Cumulative Distribution values for Kumasi

From the results the measured 1-minute rain rate for $0.01 \%$ for Kumasi was $74.7 \mathrm{~mm} / \mathrm{h}$, while the predicted ITU-R and Moupfouma rain rates were 64.6 and $106.4 \mathrm{~mm} / \mathrm{h}$ respectively, resulting in relative errors of $13.4 \%$ and $42.4 \%$ respectively. The relative error was obtained based on the recommendation of ITU-R P.311-12, (2005) as

$\varepsilon=\frac{R(p)_{\text {predicted }} R(p)_{\text {measured }}}{R(p)_{\text {measured }}} 100 \% \quad, \ldots . .0 .001 \%<\mathrm{p}<$

Where $R=(p)$ is the rain rate at a specific time percentage, $p$.

\section{DEVELOPMENT OF RAIN RATE AND RAIN ATTENUATION GEOGRAPHICAL MAPS FOR GHANA}

Many researchers have placed emphasis on rain rate and rain attenuation geographical maps. Mapping has been used in presenting the results of rain rate and attenuation for USA (Dutton and Dougherty, 1979), Europe (Dutton and Dougherty, 1979; Emiliani et al., 2004), Malaysia (Chebil and Rahman, 1999). In Africa mapping has also been used to present results for Nigeria (Ajayi, 1996; Ojo et ai.2008,2009) and South Africa (Ojo and Owolawi, 2014). This section presents the most important results on the rain rate and attenuation at $\mathrm{Ku}$ band for Ghana for the first time. The main aim of this study is to provide a preliminary tool for system designers for microwave applications at $\mathrm{Ku}$ band downlink frequencies particularly in the case of Ghana. The Moupfouma rain rate model in Equations (1) to (4) was used to convert daily rainfall data to 1 -minute rain rate statistics at all 22 synoptic stations. The ITU-R rain rate model was also applied in all 22 synoptic stations to obtain 1-minute rain rate statistics. Local measurement of 1-minute rain rate was then carried out experimentally in one of the synoptic stations compare with prediction models. Results showed that the ITU-R model gave a closer prediction to the measured data using the Cumulative Distribution of rain rates. The ITU-R model was therefore chosen to be suitable for prediction in the Ghanaian tropical climate and was used as input to the ITU-R rain attenuation model. Table 4 shows the results obtained from applying the Moupfouma and ITU-R rain rate models as well as the rain attenuation using the ITU-R rain attenuation model. 
Table 4. $R_{0.01}$ and Attenuation values for 22 synoptic stations in Ghana using Moupfouma and ITU-R rain rate and attenuation models.

\begin{tabular}{|c|c|c|c|c|c|}
\hline STATIONS & LATITUDE & LONGITUDE & ITU-R $(\mathbf{m m} / \mathbf{h})$ & $\begin{array}{l}\text { MOUPFUOMA } \\
(\mathrm{mm} / \mathrm{h})\end{array}$ & $\begin{array}{c}\text { ITU-R } \\
\text { ATTENUATION(dB) }\end{array}$ \\
\hline NAVRONGO & 10.8941 & -1.0921 & 49.8792 & 96.32 & 19.08049371 \\
\hline WA & 10.0601 & -2.5099 & 53.9679 & 97.1845 & 21.89047944 \\
\hline TAMALE & 9.4034 & -0.8424 & 50.4067 & 98.067 & 19.80296162 \\
\hline BOLE & 9.03221 & -2.4851 & 53.1707 & 100.37 & 22.44795152 \\
\hline YENDI & 9.44511 & $\begin{array}{l}-0.0093 \\
\end{array}$ & 51.8200 & 103.999 & 20.43631458 \\
\hline KUMASI & 6.6666 & -1.6163 & 64.6355 & 106.44 & 24.05834455 \\
\hline SUNYANI & 7.3349 & -2.3123 & 62.9224 & 103.68 & 26.24745823 \\
\hline $\begin{array}{l}\text { SEFWI- } \\
\text { BEKWAI }\end{array}$ & 6.19811 & -2.3246 & 71.9832 & 106.63 & 27.62476986 \\
\hline WENCHI & 7.7421 & -2.1008 & 60.1910 & 104.91 & 24.5551394 \\
\hline $\begin{array}{c}\text { KETE- } \\
\text { KRACHI }\end{array}$ & 7.8014 & -0.0513 & 59.7351 & 104.385 & 21.46269287 \\
\hline ABETIFI & 6.4011 & -0.45101 & 67.4187 & 104.236 & 25.28087864 \\
\hline AKUSE & 6.0903 & 0.1235 & 74.3556 & 95.783 & 25.08713351 \\
\hline HO & 6.6101 & 0.4785 & 65.8095 & 101.842 & 24.78305564 \\
\hline KOFORIDUA & 6.0784 & -0.2714 & 74.8765 & 101.4673 & 25.2816204 \\
\hline AKIM-ODA & 5.9296 & -0.9725 & 69.5637 & 107.103 & 25.61150222 \\
\hline AKATSI & 6.07101 & 0.48101 & 74.8765 & 92.176 & 24.81833029 \\
\hline ACCRA & 5.6037 & -0.1871 & 79.9807 & 87.781 & 26.36125129 \\
\hline TEMA & 5.7348 & 0.0302 & 84.4658 & 87.12 & 28.7759128 \\
\hline AXIM & 4.8665 & -2.2409 & 79.8906 & 113.85 & 29.8302709 \\
\hline SALTPOND & 5.2023 & -1.0514 & 77.2589 & 93.117 & 28.44596309 \\
\hline ADA-FOAH & 5.7797 & 0.6181 & 79.9235 & 91.149 & 25.53042187 \\
\hline TAKORADI & 4.9016 & $\begin{array}{l}-1.7831 \\
\end{array}$ & 82.8924 & 98.438 & 28.92231458 \\
\hline
\end{tabular}

The ITU-R rain rate values, $R_{0.01}$, was then used as input in the ITU-R rain attenuation model. The results are shown in Table 4. The software used for the mapping is ArcGIS and the technique used is the inverse-distance-squared weighting method as reported of Emiliani et al. (2004) and Miras-Avalos et al.(2007). Figure 5 shows the rain rate intensity maps obtained using the ITU-R rain rate prediction model for $0.01 \%$ and Figure 6 present the intensity maps using the ITU$\mathrm{R}$ rain attenuation model for $0.01 \%$ of time. 


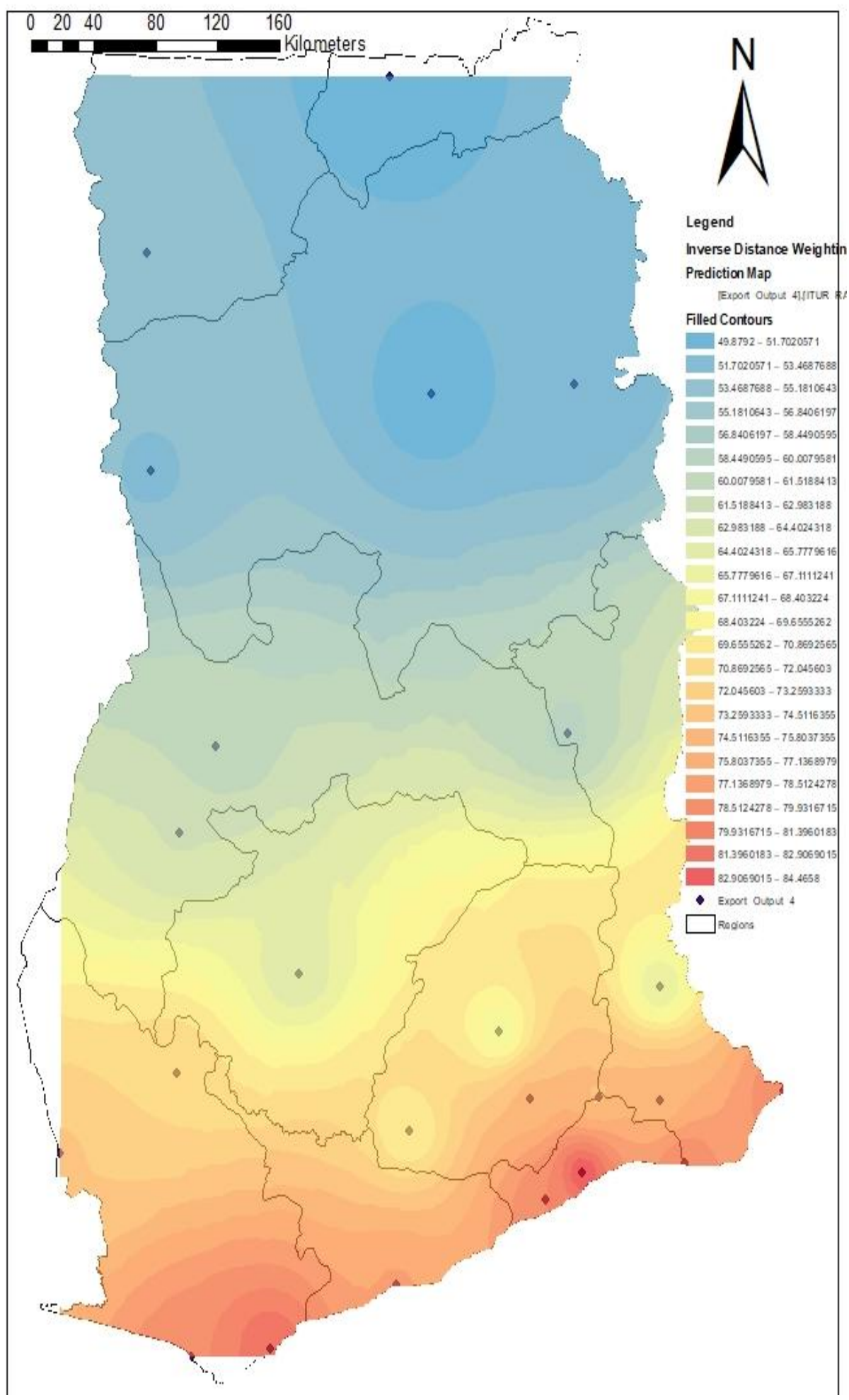

Fig 5. Rain rate maps at $0.01 \%$ of time using the ITU-R model. 


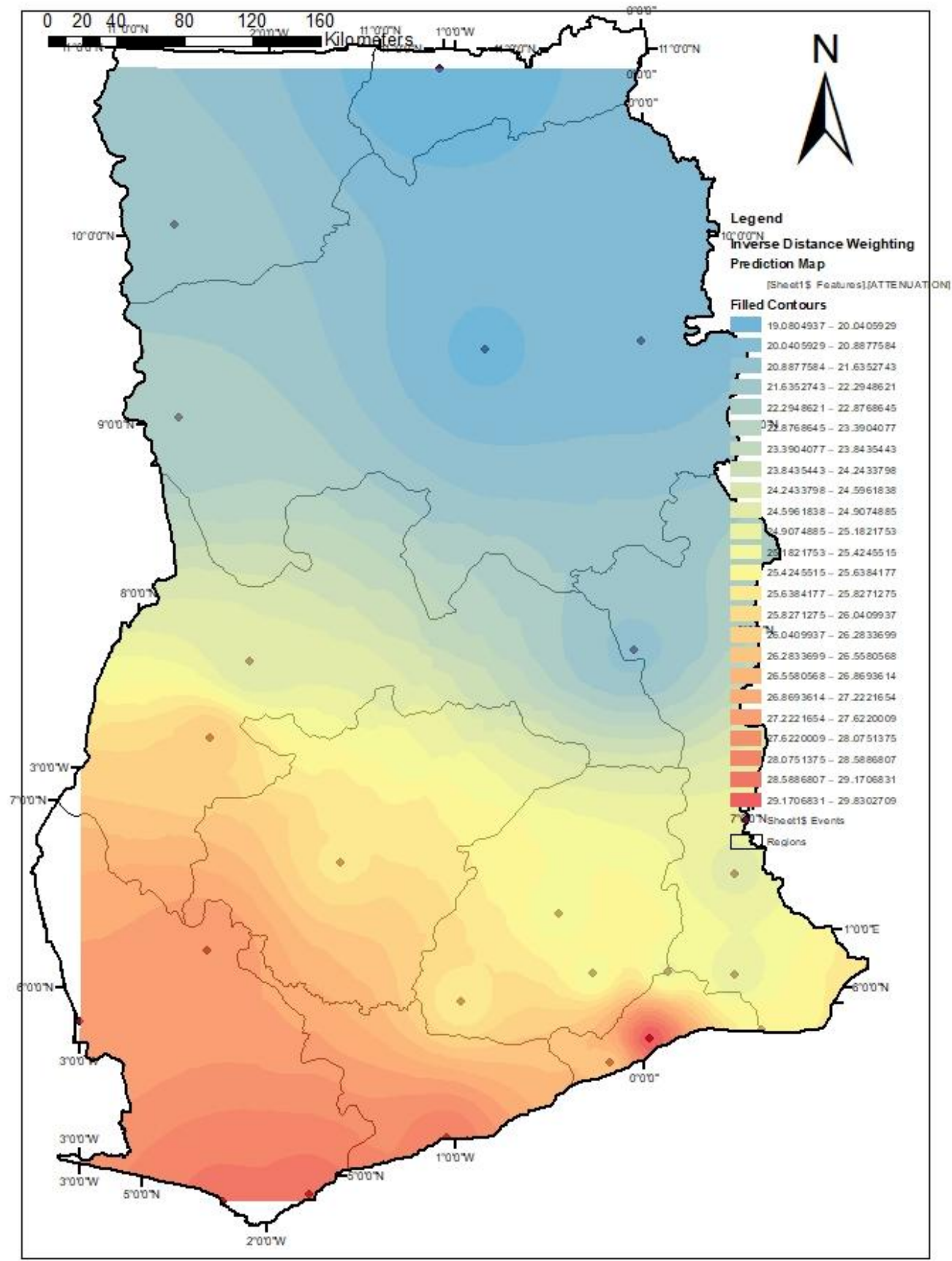

Fig 6. Rain attenuation map for $0.01 \%$ of time using the ITU-R rain attenuation model.

\section{DISCUSSION}

The Moupfouma and ITU-R rain rate models have been applied to all 22 synoptic stations in Ghana. From the results, it can be seen that Moupfouma predicts higher rain rates than ITU-R for the same locations. But when compared with measured local 1-minute data for Kumasi, it was seen that ITU-R predicted closer to the measured data. Therefore it can be concluded that Moupfouma overestimates rain rate for Kumasi. And since ITU-R predicts closer to the measured and the experiment cannot be conducted in for all locations, it will be prudent to assume that the ITU-R rain rate model performs better in Ghana. It is also observed that over the years rainfall trend in Ghana has seen a consistent decline. Available research suggests a departure from the normal trend. The reason could be due to effects of global warming. This is evident in a research conducted by Nkrumah, F. et al. (2014) which observed the rainfall variability over a 19 year period. The results showed a negative departure of rainfall implying a consistent downward trend was observed for most of the stations.

From the rain rate maps in figure 5 it is observed that the Northern part of Ghana had low rain rate values, between 49 and $53 \mathrm{~mm} / \mathrm{h}$ for $0.01 \%$ of time. This is followed by the middle zone with rain rates between 59 and $72 \mathrm{~mm} / \mathrm{h}$. Higher rain rate values were predicted in the southern and coastal region ranging between 65 and $74 \mathrm{~mm} / \mathrm{h}$ for the south and 79 and $84 \mathrm{~mm} / \mathrm{h}$ for the coast. The least rainfall rate was in Navrongo with $49.87 \mathrm{~mm} / \mathrm{h}$. The highest was in Axim a coastal town with $84.47 \mathrm{~mm} / \mathrm{h}$. Results for the rain attenuation also follows a similar pattern as the rain rate. Lower attenuation values were obtained for the Northern zone with 
an average of $20.73 \mathrm{~dB}$. There was a sharp increase in attenuation for the middle zone, with an average value of $24.87 \mathrm{~dB}$, a difference of about $4 \mathrm{~dB}$. There was not much difference in attenuation between the middle and southern zones. The average attenuation value for the south was 25.41 $\mathrm{dB}$. The highest average attenuation of $27.98 \mathrm{~dB}$ was obtained in the coastal zone. This is probably due to the high rain rates in the region especially for Axim. The result of this study suggests some differences in the attenuation levels for different climatic zones. Receivers of satellite services in these locations will be imparted differently. Hence system designers must consider these differences because the uncertainty might lead to an over-cost, both in initial expenses and in periodic expenses (Emiliani et. Al.,2004; Ojo et al.,2009). Larger antennas and better amplifiers can be used for optimum link performance in such areas.

\section{CONCLUSION}

Rain rates and rain attenuation values for $99.99 \%$ availability of time ( $0.01 \%$ unavailability) have been obtained for Ghana using the ITU-R rain rate and attenuation models. The result was used to develop rain rate and rain attenuation geographical maps for Ghana using the inverse-distance weighting method with Arc GIS software. Knowledge of the attenuation values can lead to the development of a link budget design for the various climatic zones in Ghana. This will help in determining the additional power margin required to compensate for the effect of rain for each climatic zone. Since one of the mitigation techniques is to increase the transmitted power. This step is necessary because Ghana is migrating from analogue to digital satellite television broadcasting and rain will be the major cause of signal impairment. Hence, $\mathrm{Ku}$ band satellite signals will likely be unavailable for most part of the year. This results will serve as a tool for system designers in the planning of satellite services and receiver characteristics for Ghana.

\section{APPENDIX A}

The step-by-step procedure for calculating the attenuation distribution is given below:

Step 1: Freezing height during rain $H_{r}(\mathrm{~km})$ is calculated from the absolute value of station latitude $\varphi$ (degrees), preferably using the location under study.

Step 2: The slant path length, $L_{s}$, below the freezing rain height is obtained:

$L_{S}(\theta)= \begin{cases}\frac{\left(h_{R}-h_{S}\right)}{\sin \theta} & \text { for } \theta \geq 5^{o} \\ \frac{2\left(h_{R}-h_{S}\right)}{\left[\sin ^{2} \theta+\frac{2\left(h_{r}-h_{S}\right)}{R_{e}}\right]^{1 / 2}+\sin \theta} & \text { for } \theta<5^{o}(\mathrm{~km})\end{cases}$

where $h_{R}=$ the rain height $(\mathrm{km})$, from Step $1 ; h_{S}=$ the altitude of the ground receiver site from sea level $(\mathrm{km}) ; \theta=$ the elevation angle; and $R_{E}=8500 \mathrm{~km}$ (effective earth radius). $L_{S}$ can result in negative values when the rain height is smaller than the altitude of the ground receiver site. If a negative value occurs, $L_{S}$ is set to zero.

Step 3: The horizontal projection is calculated as

$L_{G}=L_{S} \cos \theta$

where $L_{S}$ and $L_{G}$ are in $\mathrm{km}$.

Step 4: The rain intensity, $R_{0.01}(\mathrm{~mm} / \mathrm{h})$, exceeded for $0.01 \%$ of an average year is then obtained from the 1 -minute integration rain-rate data and is used for calculating the specific attenuation, $\gamma_{0.01}(\mathrm{~dB} / \mathrm{km})$ :

$\gamma_{R}=k R_{0.01}^{\propto}$

The parameter $k$ and $\propto$ depend on frequency, raindrop size distribution, rain temperature and polarization. These can be obtained from ITU-R P. 838-5,2005.

Step 5: The horizontal path adjustment factor, $r_{0.01}, 0.01 \%$ of the time is also given as :

$r_{0.01}=\frac{1}{1+0.78 \sqrt{\frac{L_{G} \gamma_{R}}{f}}-0.38\left(1-e^{-2 L_{G}}\right)}$

Step 6: Calculate the vertical adjustment factor, $v_{0.01}$, for $0.01 \%$ of the time

$v_{0.01}=\frac{1}{1+\sqrt{\sin \theta}\left[31\left(1-e^{-(\theta / 1+x)}\right) \frac{\sqrt{L_{R} \gamma_{R}}}{f^{2}}-0.45\right]}$

where

$L_{R}= \begin{cases}\frac{L_{G} r_{0.01}}{\cos \theta} & k m \text { for } \zeta>\theta \\ \frac{\left(h_{R}-h_{S}\right)}{\sin \theta} & k m \text { for } \zeta \leq \theta\end{cases}$

and

$$
\begin{aligned}
\zeta & =\tan ^{-1}\left(\frac{h_{R}-h_{S}}{L_{G} r_{0.01}}\right) \operatorname{deg} \\
& x=36-|\varphi| \text { deg } \quad \text { for }|\varphi|<36 \\
& =0 \text { for }|\varphi| \geq 36
\end{aligned}
$$

Step 7: Determine the effective path length, $L_{E}(\mathrm{~km})$, is given by:

$L_{E}=L_{R} v_{0.01} \mathrm{~km}$

Step 8: The predicted attenuation exceeded for $0.01 \%$ of an average year may then be obtained from:

$A_{0.01}=\gamma_{R} L_{E} \quad \mathrm{~dB}$

Step 9: The attenuation $A_{p}$, exceeded for the other percentages, $p$, of an average year, in the range 0.001-5\%, can be determined from

$A_{P}=$
$A_{0.01}\left(\frac{P}{0.01}\right)^{-\left[0.655+0.033 \ln (p)-0.045 \ln \left(A_{0.01}\right)-\beta(1-p) \sin \theta\right]}$
$\mathrm{dB}$

where

$\beta$

$=\left\{\begin{array}{lr}0 & \text { if } p \geq 1 \% \text { or }|\varphi| \geq 36^{\circ} \\ -0.005(|\varphi|-36) & \text { if } p<1 \% \text { and }|\varphi|<36^{\circ} \text { and }\end{array}\right.$

$=\left\{\begin{array}{lr}-0.005(|\varphi|-36) & \text { if } p<1 \% \text { and } \\ -0.005(|\varphi|-36)+1.8-4.25 \sin \theta & \text { otherwise }\end{array}\right.$

(A12)

\section{REFERENCES}

[1] Ajayi, G.O. (Ed.), (1996). Handbook on radio propagation related to satellite communications in tropical and subtropical countries, Trieste, Italy, URSI Standing Committee on Developing Countries and International Center for Theoretical Physics.

[2] Emiliani, L. D., Agudelo, J., Gutierrez, E., Restrepo, J., Fradique-Mendez, C., (2004). Development of rainattenuation and rain-rate maps for satellite system design 
in the $\mathrm{Ku}$ and $\mathrm{Ka}$ bands in Colombia. IEEE Antenna Propag. Mag. 46 (6), 54-68.

[3] Ippolito J. Louis (1986), Radiowave Propagation in Satellite Communications, Van Nostrand Reinhold Company, New York.

[4] Ippolito J. Louis, Satellite Communications Systems Engineering (2008), John Wiley and Sons Ltd, New York, ISBN 978-0-470-72527-6 (HB)

[5] ITU-R Recommendation 837-5,6, (2012), Characteristics of Precipitation for Propagation Modelling, Geneva.

[6] ITU-R Recommendation 838-3, (2005), "Specific attenuation model for rain use in prediction methods"

[7] ITU-R Recommendation P. 841-4 (2005), Conversion of annual statistics to worst-month statistics, Geneva.

[8] ITU-R Recommendation P.618-8 (2003). "Propagation data and prediction methods required for the design of earth-space telecommunication systems", International Telecommunications Union, Geneva, April 2003.
[9] Moupfouma, F.,1985, Feb. Model of rainfall-rate distribution for radio system design. In: IEEE Proceedings, vol. 132, Pt. H, No. 1, pp. 39-43.

[10] Nkrumah, F., et al. (2014) Rainfall Variability over Ghana: Model versus Rain Gauge Observation, International Journal of Geosciences, 5, 673-683.

[11] Ojo, J. S., Ajewole, M. O., Emiliani, L. D., (2009). Oneminute rain rate contour maps for communication system planning in a tropical country: Nigeria. IEEE Antennas Propag. Mag. 5, 207-223.

[12] Ojo, J. S., Omotosho, T. V., (2013). Comparison of 1min rain rate derived from TRMM satellite data and rain guage data for microwave applications in Nigeria. J. Atmos. Sol. Terr. Phy. 102, 17-25.

[13] W. L. Pritchard and J.A. Sciulli (1986), Satellite Communication Systems Engineering, Prentice-Hall, Englewood Cliffs, NJ. 